\title{
$\mathrm{OFDMA}$ 시스템을 위한 다중 셀 전송 다양성 기법 \\ 서 방 원"
}

\section{Multi-Cell Transmit Diversity Scheme for OFDMA Systems}

\author{
Bangwon Seo
}

요 약

기존의 다중 셀 전송 다양성 기법의 경우, 단말기는 채널 상태가 가장 좋은 송신 안테나에 대한 인덱스를 기지 국으로 피드백하고, 각 기지국은 그 정보에 의해 한 개의 송신 안테나만을 이용하여 다중 셀 전송 다양성 기법을 적용한다. 그러나, 채널이 빠르게 변하는 경우에는 단말기의 피드백 시점과 기지국의 데이터 스케줄링 시점의 채 널이 매우 달라지게 된다. 또한, 기지국에 장착된 송신 안테나들은 보통 개별적인 전력 증폭기를 가지고 있기 때 문에, 한 개의 송신 안테나만을 사용할 경우 가용 전력의 일부만을 사용하게 되어서 전체 성능이 감소하게 된다. 따라서, 본 논문에서는 기지국이 단말기의 피드백 정보에 의존하지 않고 모든 송신 안테나들을 동시에 사용하는 프리코딩 벡터 기반의 다중 셀 전송 다양성 기법을 제안한다. 제안하는 방법에서는 이웃한 부반송파들 간에 서로 다른 프리코딩 벡터를 적용함으로써, 수신 신호가 넓은 대역에 걸쳐서 큰 채널 감쇄 현상을 겪는 것을 회피하게 된다. 모의 실험을 통하여, 단말기의 이동 속도가 빠른 경우에는 제안하는 방법이 기존 방법보다 더 우수한 성능 을 나타낸다는 것을 보인다.

Key Words : MIMO, 다중 셀, 시공간 블록코드, STBC, 전송 다양성 기법, 프리코딩

\section{ABSTRACT}

Since a conventional multi-cell transmit diversity scheme depends on the feedback from the user for the channel gain information, its performance gets to severely degrade when the channel varies fast due to the high mobility of the user. Also, transmit power of the base station cannot be fully used in the conventional scheme because only one transmit antenna is used for data transmission. In this paper, we propose a multi-cell transmit diversity scheme appropriate for fast fading channel. In the proposed scheme, channel-independent precoding vector is applied over all transmit antennas and different precoding vectors are applied for neighboring subcarriers so that the received signal is avoided to experience deep fading over multiple neighboring subcarriers. Simulation results show that the proposed scheme has better detector output signal-to-noise ratio (SNR) and bit error rate (BER) performances than the conventional scheme.

\section{I. 서 론}

최근에 다중 안테나를 이용한 다중 입력 다중 출 력 (Multiple-input multiple output: MIMO) 시스템 에 대한 많은 연구가 진행되었다. MIMO 기법은 데이터 전송률을 높이는 것을 목적으로 하는 공간
다중화 (Spatial multiplexing) 기법과 데이터 신뢰도 를 높이는 것을 목적으로 하는 전송 다양성 (Transmit diversity) 기법으로 나눌 수 있다 ${ }^{[1,2]}$. 이 동 통신 시스템에서 기지국이 채널에 대한 모든 정 보 또는 일부 정보를 알고 있는 경우에는 공간 다 중화 기법을 적용할 수 있으며, 기지국이 채널에 대

- 주저자 : 한국전자통신연구원 차세대통신연구부문 이동통신방식연구팀, seobw@etri.re.kr, 정회원 논문번호 : KICS2012-03-138, 접수일자 : 2012년 3월 26일, 최종논문접수일자 : 2012년 9월 5일 
한 정보를 얻는 방법으로는 단말기가 채널을 추정 한 후에 관련 정보를 기지국으로 피드백해 주는 방 법이 있다. 이러한 방법은 채널이 상대적으로 천천 히 변해서 단말기가 채널 정보를 피드백하는 시점 과 기지국이 그 정보를 이용하여 데이터를 스케줄 링하는 시점 사이에 채널 변화가 크지 않은 경우에 만 적용이 가능하다. 그러나, 고속으로 움직이는 단 말기의 경우 채널이 시간에 따라서 빠르게 변하기 때문에, 단말기가 피드백하는 시점에서의 채널 값과 기지국이 그 단말기에게 데이터를 전송하는 시점에 서의 채널 값이 많이 다를 수 있다. 이런 경우에는 기지국이 데이터 전송 시점에서의 채널 값을 아는 것은 매우 어렵다.

이와 같이 채널이 빠르게 변하는 환경에서, 기지 국이 채널 정보 없이 데이터의 신뢰도를 높일 수 있는 방법으로는 다중 안테나를 이용한 전송 다양 성 기법이 있다. 전송 다양성을 얻는 기법들 중에 가장 대표적인 예는 Alamouti에 의해서 제안된 시 공간 블록 부호 (Space-time block code, STBC) 기 법이다 ${ }^{[3]}$. STBC 방식은 송신 안테나 개수가 2개인 경우에는 간단한 수신 기법을 통해서 송신 안테나 간의 간섭을 완전히 제거할 수 있으며, 최대 부호율 (Full code rate)과 최대 다양성 (Full diversity)을 얻을 수 있다. 그러나, 송신 안테나 개수가 2개보다 많은 경우에는 이러한 특성을 완벽하게 얻을 수 없 다는 것이 일반적으로 알려져 있다 ${ }^{[4,5]}$.

한편, 셀룰러 이동통신 환경에서 셀 경계 사용자 는 주변 셀로부터 많은 간섭을 받기 때문에 성능이 크게 떨어질 수 있다. 이러한 셀간 간섭 문제를 해 결하기 위한 방법으로서 주파수 부분 재사용 (Fractional frequency reuse: FFR) 기법이 제안되었 다다. 이 방법은 셀 근처에 존재하는 단말기와 셀 경계에 존재하는 단말기에게 서로 다른 주파수를 할당하고, 또한 셀 경계에 존재하는 단말기에게 할 당하는 주파수를 각 셀마다 다르게 설정함으로써 셀간 간섭을 회피하는 방법이다. 그러나, 이 방법은 기지국의 스케줄링에 많은 제약이 생기고 성능 향 상도 매우 제한적인 단점이 있다.

최근에 셀 경계 단말기에 대한 성능을 향상시키 기 위한 방법으로 다중 셀 협력 프리코딩 기법들이 제안되었다 ${ }^{[7,8]}$. 그러나, 이러한 방법들은 협력 기지 국들이 채널에 대한 정보를 미리 알고 있어야 되기 때문에, 본 논문에서 고려하는 채널이 빨리 변하는 환경에서는 적용이 어려운 기법들이다. 따라서, 채 널이 빨리 변하는 환경에 적합한 다중 셀 협력 전
송 기법으로서 다중 셀 전송 다양성 기법이 제안되 었다 ${ }^{[9]}$. 이 방법에서는 두 개의 기지국이 협력하여 $\mathrm{STBC}$ 기법을 적용하기 위하여, 각 기지국이 여러 개의 송신 안테나 중에서 채널 상태가 가장 좋은 한 개의 송신 안테나만을 사용해서 전송하는 기법 이다. 이 때, 각 기지국이 한 개의 송신 안테나를 선택하기 위하여, 단말기는 채널 이득이 가장 큰 송 신 안테나에 대한 정보를 기지국으로 피드백하게 된다. 이 방법은 다중 셀 협력 프리코딩 기법들에 비해서 더 적은 피드백 오버헤드를 필요로 하고 채 널 이득의 크기에만 관련이 있기 때문에 채널 변화 에 덜 민감하다는 장점이 있다. 따라서, 저속이나 중속 (Medium speed)으로 움직이는 단말기에게 적 용이 가능한 기법이다. 그러나, 이 방법도 여전히 단말기의 피드백 정보에 의존해서 송신 안테나를 선택하기 때문에, 고속으로 움직여서 채널이 빨리 변하는 단말기에는 적용이 어려운 기법이다. 또한, 기지국에 장착된 송신 안테나들은 보통 개별적인 전력 증폭기들을 가지고 있기 때문에, 한 개의 송신 안테나만을 사용하여 데이터를 전송하게 되면 사용 가능한 송신 전력 중의 일부만을 사용하게 되는 단 점이 발생하게 된다.

본 논문에서 제안하는 기법은 채널이 빨리 변하 는 환경에 적용하기 위한 기술로서, 기지국에서 채 널에 대한 정보를 전혀 필요로 하지 않으면서 모든 송신 안테나들을 동시에 이용하는 다중 셀 전송 다 양성 기법이다. 제안하는 방법에서는 각 기지국이 모든 송신 안테나에 대해서 미리 정해진 프리코딩 벡터를 적용하고, 이웃한 부반송파 간에는 서로 다 른 프리코딩 벡터를 적용함으로써, 이웃한 여러 개 의 부반송들이 동시에 큰 채널 감쇄 현상을 겪는 것을 회피하게 된다. 즉, 이웃한 부반송파 간에는 채널 상태가 비슷해서, 이 부반송파들에 대해서 동 일한 프리코딩 벡터를 적용할 경우 모두 큰 채널 감쇄 현상을 겪을 수 있기 때문이다. 이 때, 기지국 과 단말기 간에 미리 정해진 순서대로 프리코딩 벡 터들을 적용함으로써, 기지국이 단말기에게 프리코 딩 벡터에 대한 정보를 알려줄 필요가 없도록 한다. 또한, 이 방법에서는 모든 송신 안테나를 이용하기 때문에, 사용 가능한 송신 전력을 모두 이용할 수 있고 검파기 출력단에서 신호대 잡음비 (Signal-to -noise ratio: SNR) 이득을 더 얻게 된다.

본 논문의 구성은 다음과 같다. II장에서는 기존 의 다중 셀 전송 다양성 기법에 대해서 살펴본다. III장에서는 채널이 빨리 변하는 환경에 적합한 다 
중 셀 전송 다양성 기법을 제안한다. IV장에서는 모의 실험을 통하여, 제안한 전송 기법과 기존 기법 의 성능을 비교한다. 마지막으로 $\mathrm{V}$ 장에서는 결론을 맺는다.

\section{II. 기존의 다중 셀 전송 다양성 기법}

본 장에서는 [9]에서 제안된 기존의 시공간 부호 코드를 이용한 다중 셀 전송 다양성 기법에 대해서 설명한다. 그림 1 은 이러한 기존 방법에 대해 설명 하는 그림이다. 셀 1 의 경계에 존재하는 사용자 $\mathrm{UE}_{0}$ 의 성능을 향상시키기 위하여 셀 1 과 셀 2 의 기지국이 협력하여 다중 셀 전송 다양성 기법을 적 용한다고 가정하자. 각 기지국의 송신 안테나 개수 는 $\mathrm{M}$ 개이고, $\mathrm{UE}_{0}$ 에서의 수신 안테나 개수는 설명 의 편의상 1 개라고 가정한다. 그러나, 수신 안테나 의 개수가 여러 개인 경우에도 쉽게 확장이 가능하 다.

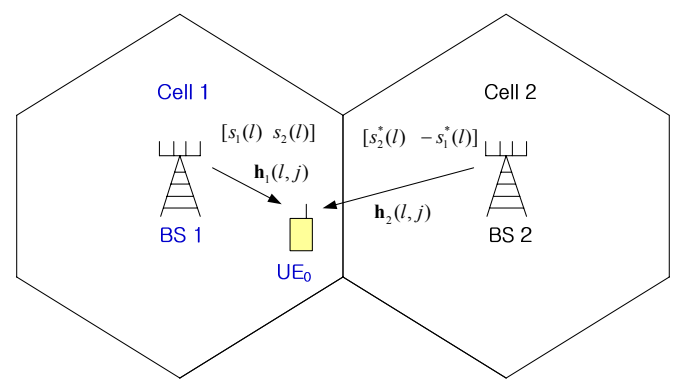

그림 1. 기존의 다중 셀 전송 다양성 기법

Fig. 1. Conventional multi-cell transmit diversity scheme

직교 주파수 분할 다중 접속 (Orthogonal frequency division multiple access: OFDMA) 환경 을 고려하기 때문에, 각 부반송파 대역에서의 채널 은 주파수에 대해서 평평하다고 (Frequency-flat fading) 가정한다. 그리고, $\mathrm{UE}_{0}$ 는 부반송파 집합 $A=\left\{l_{0}, l_{0}+1, \cdots, l_{0}+L-1\right\}$ 에 대하여 채널을 추정 하고, 그 정보를 기지국으로 피드백한다고 하자. 집 합 $A$ 에 속하는 부반송파 $l$ 에 대하여, 시간 슬롯 $j$ 에 서 기지국 $k \quad(k=1,2)$ 로부터 $\mathrm{UE}_{0}$ 까지의 채널을 $\mathrm{h}_{k}(l, j)=\left[h_{k, 1}(l, j), \cdots, h_{k, M}(l, j)\right]^{T}$ 라고 하자.

$\mathrm{UE}_{0}$ 는 시간 슬롯 $j=J_{1}$ 에서, 각 기지국으로부터 수신된 훈련 심볼들을 이용하여 $\mathrm{h}_{1}\left(l, J_{1}\right)$ 과 $\mathrm{h}_{2}\left(l, J_{1}\right)$ 을 추정하고, 다음 식과 같이 채널 이득이 가장 큰 송신 안테나 인덱스를 찾는다.

$$
m_{\mathrm{opt}, k}(l)=\underset{m \in\{1,2, \cdots, M\}}{\arg \max }\left|h_{k, m}\left(l, J_{1}\right)\right|, k=1,2, l \in A .
$$

그리고, 이 정보를 기지국으로 피드백하게 된다. 이 때, 각 부반송파별로 필요한 피드백 비트 수는 $2\left\lceil\log _{2} M\right\rceil$ 이고, 총 $L$ 개의 부반송파를 위해서 필 요한 비트 수는 $2 L\left\lceil\log _{2} M\right\rceil$ 이다. 따라서, $L$ 이 클 수록 너무 많은 비트 수를 필요로 하기 때문에, 피 드백 양을 줄이기 위하여 다음과 같이 $A$ 에 속하는 모든 부반송파들에 대한 채널 이득의 합이 가장 큰 송신 안테나 인덱스를 찾는다.

$$
m_{\mathrm{opt}, k}=\underset{m \in\{1,2, \cdots, M\}}{\arg \max } \sum_{l=l_{0}}^{l_{0}+L-1}\left|h_{k, m}\left(l, J_{1}\right)\right|, \quad k=1,2 .
$$

기지국이 $m_{\mathrm{opt}, k}$ 정보를 이용하여 $\mathrm{UE}_{0}$ 에게 데이 터를 스케줄링하고, $\mathrm{UE}_{0}$ 가 그 데이터를 받는 시간 슬롯을 $j=J_{2}$ 라고 하자. 이 때, $\mathrm{STBC}$ 를 적용하기 위하여 기지국 1 과 2 는 각각 송신 안테나 $m_{\mathrm{opt}, 1}$ 와 $m_{\mathrm{opt}, 2}$ 를 이용하여 $s_{1}(l)$ 과 $s_{2}^{*}(l)$ 을 전송한다. 그러 면, 수신 신호는 다음과 같이 쓸 수 있다.

$$
\begin{aligned}
r\left(l, J_{2}\right)= & h_{1, m_{\mathrm{opt}, 1}}\left(l, J_{2}\right) s_{1}(l) \\
& +h_{2, m_{\mathrm{opt}, 2}}\left(l, J_{2}\right) s_{2}^{*}(l)+z\left(l, J_{2}\right) .
\end{aligned}
$$

여기에서 $z\left(l, J_{2}\right)$ 는 평균이 0 이고, 분산이 $\sigma_{z}^{2}$ 인 백색 가우시안 부가잡음 (Additive white Gaussian noise: AWGN)을 나타낸다.

또한, 시간 슬롯 $j=\left(J_{2}+1\right)$ 에서는 기지국 1 과 2 는 각각 송신 안테나 $m_{\mathrm{opt}, 1}$ 와 $m_{\mathrm{opt}, 2}$ 를 이용하여 $s_{2}(l)$ 과 $-s_{1}^{*}(l)$ 을 전송하고, 수신 신호는 다음과 같이 쓸 수 있다.

$$
\begin{aligned}
& r\left(l, J_{2}+1\right)=h_{1, m_{\mathrm{opt}, 1}}\left(l, J_{2}+1\right) s_{2}(l) \\
& \quad-h_{2, m_{\mathrm{opt}, 2}}\left(l, J_{2}+1\right) s_{1}^{*}(l)+z\left(l, J_{2}+1\right) .
\end{aligned}
$$

두 시간 슬롯구간 동안에 채널이 거의 변하지 않 는다고 가정하면, $h_{1, m_{\mathrm{opt}, 1}}\left(l, J_{2}\right) \approx h_{1, m_{\mathrm{opt}, 1}}\left(l, J_{2}+1\right)$ 이고, $h_{2, m_{\mathrm{opt}, 2}}\left(l, J_{2}\right) \approx h_{2, m_{\mathrm{opt}, 2}}\left(l, J_{2}+1\right)$ 이다. 따라서, $r\left(l, J_{2}\right)$ 과 $r\left(l, J_{2}+1\right)$ 을 이용하여, $s_{1}(l)$ 과 $s_{2}(l)$ 을 추정하기 위한 검파 과정은 다음과 같다. 


$$
\begin{aligned}
\hat{s}_{1}(l)= & h_{1, m_{\text {opt }, 1}}^{*}\left(l, J_{2}\right) r\left(l, J_{2}\right) \\
& -h_{2, m_{\text {opt }, 2}}\left(l, J_{2}\right) r^{*}\left(l, J_{2}+1\right) \\
= & \left(\left|h_{1, m_{\text {opt }, 1}}\left(l, J_{2}\right)\right|^{2}+\left|h_{2, m_{\text {op }, 2}}\left(l, J_{2}\right)\right|^{2}\right) s_{1}(l) \\
& +z_{1}\left(l, J_{2}+1\right) . \\
\hat{s}_{2}(l)= & h_{1, m_{\text {opt }, 1}}\left(l, J_{2}\right) r^{*}\left(l, J_{2}\right) \\
& +h_{2, m_{\mathrm{opt}, 2}}\left(l, J_{2}\right) r\left(l, J_{2}+1\right) \\
= & \left(\left|h_{1, m_{\mathrm{opt}, 1}}\left(l, J_{2}\right)\right|^{2}+\left|h_{2, m_{\mathrm{op}, 2}}\left(l, J_{2}\right)\right|^{2}\right) s_{2}(l) \\
& +z_{2}\left(l, J_{2}+1\right) .
\end{aligned}
$$

여기에서, $z_{1}\left(l, J_{2}+1\right)$ 과 $z_{2}\left(l, J_{2}+1\right)$ 은 다음과 같이 주어진다.

$$
\begin{aligned}
& z_{1}\left(l, J_{2}+1\right) \\
& =h_{1, m_{\mathrm{opt}, 1}}^{*}\left(l, J_{2}\right) z\left(l, J_{2}\right)-h_{2, m_{\mathrm{opt}, 2}} z\left(l, J_{2}+1\right) . \\
& z_{2}\left(l, J_{2}+1\right) \\
& =h_{2, m_{\mathrm{opt}, 2}}\left(l, J_{2}\right) z^{*}\left(l, J_{2}\right)+h_{2, m_{\mathrm{opt}, 2}}^{*} z\left(l, J_{2}+1\right) .
\end{aligned}
$$

따라서, 기존 방법에 대한 검파기 출력에서의 $\mathrm{SNR}$ 은 두 심볼에 대해서 동일하며 다음과 같이 쓸 수 있다.

$$
\begin{aligned}
& \operatorname{SNR}_{1}^{(\text {conv) }}\left(l, J_{2}\right)=\operatorname{SNR}_{2}^{(\text {conv) }}\left(l, J_{2}\right) \\
& =\frac{\left|h_{1, m_{\mathrm{opt}, 1}}\left(l, J_{2}\right)\right|^{2}+\left|h_{2, m_{\mathrm{op}, 2}}\left(l, J_{2}\right)\right|^{2}}{\sigma_{z}^{2}}, l \in A .
\end{aligned}
$$

\section{III. 제안하는 다중 셀 전송 다양성 기법}

기존 방법에서는 다중 셀 전송 다양성 이득을 얻 기 위하여 집합 $A$ 에 속하는 부반송파들에 대해 채 널 이득의 합이 가장 큰 송신 안테나의 인덱스를 기지국으로 피드백하기 때문에 총 $2\left\lceil\log _{2} M\right\rceil$ 개의 피드백 비트 수를 필요로 한다. 그리고, $\mathrm{UE}_{0}$ 가 $m_{\mathrm{opt}, k}$ 을 추정하는 시점과 실제 데이터를 전송 받는 시점 간의 차이는 $\Delta=J_{2}-J_{1}$ 이고, $\triangle$ 가 크거나 $\mathrm{UE}_{0}$ 의 이동 속도가 빨라서 채널이 시간에 따라 빨 리 변하는 경우에는 기존 방법의 성능이 떨어지게 된다. 또한, 기존 방법에서는 기지국에 장착된 송신 안테나 중에서 한 개의 송신 안테나만을 사용하기 때문에, 사용 가능한 전력 중에서 일부 전력만을 사 용하는 단점이 발생하게 된다. 즉, 일반적으로 기지 국에 장착된 송신 안테나들은 각각 개별적인 전력 증폭기를 가지고 있기 때문에, 모든 송신 안테나들 이 동시에 최대 전력으로 송신할 때 가장 좋은
SNR 성능을 얻을 수 있다.

본 장에서는 $\triangle$ 가 크거나 $\mathrm{UE}_{0}$ 의 이동 속도가 빠 른 경우에 적합한 다중 셀 전송 다양성 기법을 제 안한다. 이러한 환경에서는 가장 큰 채널을 갖는 송 신 안테나 인덱스가 시간 슬롯 $j=J_{1}$ 과 $j=J_{2}$ 에서 서로 다를 수 있기 때문에, $\mathrm{UE}_{0}$ 가 $m_{\mathrm{opt}, k}$ 에 대한 정보를 기지국으로 피드백하는 것은 의미가 없다. 따라서, 여기에서 제안하는 기법에서는 $\mathrm{UE}_{0}$ 가 채널 에 대한 정보를 기지국으로 피드백하지 않는다. 또 한, 모든 송신 안테나를 사용하도록 하기 위하여 길 이가 $M \times 1$ 인 프리코딩 벡터를 적용한다. 그리고, 기지국은 각 부반송파별로 가장 적합한 프리코딩 벡터를 알 수 없기 때문에, 여러 부반송파에 걸쳐서 큰 채널 감쇄를 겪는 것을 피하기 위하여 이웃한 부반송파 간에 서로 다른 프리코딩 벡터를 적용한 다. 프리코딩 벡터들을 적용하는 순서는 기지국과 $\mathrm{UE}_{0}$ 간에 미리 정해진 순서대로 사용한다. 따라서, 기지국은 $\mathrm{UE}_{0}$ 에게 프리코딩 벡터에 대한 정보를 시 그널링해 줄 필요는 없다.

$j=J_{2}$ 에서 기지국 $k$ 가 부반송파 $l$ 에서 적용하는 프리코딩 벡터를 $\mathrm{v}_{k}(l), k=1,2$,라고 하고, $\mathrm{v}_{k}(l)$ 을 다음과 같이 선택한다.

$\mathrm{v}_{k}(l)=\left[v_{k, 1}, \cdots, v_{k, M}\right]^{T}, \quad\left|v_{k, m}\right|=1$ for all $m$.

이 때, 기지국 1 과 2 가 각각 $s_{1}(l)$ 과 $s_{2}(l)$ 을 전 송한다고 하면, $\mathrm{UE}_{0}$ 가 받는 수신 신호는 다음과 같 이 쓸 수 있다.

$$
\begin{aligned}
r_{\mathrm{pro}}\left(l, J_{2}\right)= & \mathrm{h}_{1}^{T}\left(l, J_{2}\right) \mathrm{v}_{1}(l) s_{1}(l) \\
& +\mathrm{h}_{2}^{T}\left(l, J_{2}\right) \mathrm{v}_{2}(l) s_{2}^{*}(l)+z\left(l, J_{2}\right) \\
= & g_{1}\left(l, J_{2}\right) s_{1}(l)+g_{2}\left(l, J_{2}\right) s_{2}^{*}(l)+z\left(l, J_{2}\right) .
\end{aligned}
$$

여기에서 $g_{1}\left(l, J_{2}\right)$ 과 $g_{2}\left(l, J_{2}\right)$ 은 다음과 같이 주어진다.

$$
\begin{aligned}
g_{1}\left(l, J_{2}\right) & =\mathbf{h}_{1}^{T}\left(l, J_{2}\right) \mathrm{v}_{1}(l) \\
& =\sum_{m=1}^{M} h_{1, m}\left(l, J_{2}\right) v_{1, m}(l) . \\
g_{2}\left(l, J_{2}\right) & =\mathbf{h}_{2}^{T}\left(l, J_{2}\right) \mathrm{v}_{2}(l) \\
& =\sum_{m=1}^{M} h_{2, m}\left(l, J_{2}\right) v_{2, m}(l) .
\end{aligned}
$$

또한, 시간 슬롯 $j=\left(J_{2}+1\right)$ 에서 기지국 1 과 2 가 각각 $s_{2}(l)$ 과 $-s_{1}^{*}(l)$ 을 전송한다고 하면, $\mathrm{UE}_{0}$ 가 받는 수신 신호는 다음과 같이 쓸 수 있다. 


$$
\begin{aligned}
& r_{\mathrm{pro}}\left(l, J_{2}+1\right)=\mathrm{h}_{1}^{T}\left(l, J_{2}+1\right) \mathrm{v}_{1}(l) s_{2}(l) \\
& \quad-\mathrm{h}_{2}^{T}\left(l, J_{2}+1\right) \mathrm{v}_{2}(l) s_{1}^{*}(l)+z\left(l, J_{2}+1\right) \\
& \approx g_{1}\left(l, J_{2}\right) s_{2}(l)-g_{2}\left(l, J_{2}\right) s_{1}^{*}(l)+z\left(l, J_{2}+1\right) .
\end{aligned}
$$

여기에서, 두 시간 슬롯 구간 동안에 채널은 거 의 변하지 않는다고 가정하였다.

이제 $r_{\mathrm{pro}}\left(l, J_{2}\right)$ 과 $r_{\mathrm{pro}}\left(l, J_{2}+1\right)$ 을 이용하여, $s_{1}(l)$ 과 $s_{2}(l)$ 을 추정하기 위한 검파 과정은 다음 과 같다.

$$
\begin{gathered}
\hat{s}_{1, \mathrm{pro}}(l)=g_{1}^{*}\left(l, J_{2}\right) r_{\text {pro }}\left(l, J_{2}\right)-g_{2}\left(l, J_{2}\right) r_{\mathrm{pro}}^{*}\left(l, J_{2}+1\right) \\
=\left(\left|g_{1}\left(l, J_{2}\right)\right|^{2}+\left|g_{2}\left(l, J_{2}\right)\right|^{2}\right) s_{1}(l)+z_{1, \mathrm{pro}}\left(l, J_{2}+1\right) .
\end{gathered}
$$

$$
\hat{s}_{2, \text { pro }}(l)=g_{2}\left(l, J_{2}\right) r_{\text {pro }}^{*}\left(l, J_{2}\right)+g_{1}^{*}\left(l, J_{2}\right) r_{\text {pro }}\left(l, J_{2}+1\right)
$$$$
=\left(\left|g_{1}\left(l, J_{2}\right)\right|^{2}+\left|g_{2}\left(l, J_{2}\right)\right|^{2}\right) s_{2}(l)+z_{2, \text { pro }}\left(l, J_{2}+1\right) \text {. }
$$

여기에서, $z_{1, \mathrm{pro}}\left(l, J_{2}+1\right)$ 과 $z_{2, \mathrm{pro}}\left(l, J_{2}+1\right)$ 은 다 음과 같이 주어진다.

$$
\begin{aligned}
z_{1, \mathrm{pro}}\left(l, J_{2}+1\right)= & g_{1}^{*}\left(l, J_{2}\right) z\left(l, J_{2}\right) \\
& -g_{2}\left(l, J_{2}\right) z\left(l, J_{2}+1\right) . \\
z_{2, \mathrm{pro}}\left(l, J_{2}+1\right)= & g_{2}\left(l, J_{2}\right) z^{*}\left(l, J_{2}\right) \\
& +g_{1}^{*}\left(l, J_{2}\right) z\left(l, J_{2}+1\right) .
\end{aligned}
$$

따라서, 제안하는 기법의 검파기 출력 $\mathrm{SNR}$ 은 두 심볼에 대해서 동일하며 다음과 같이 쓸 수 있다.

$$
\begin{gathered}
\operatorname{SNR}_{1}^{(\text {pro })}\left(l, J_{2}\right)=\operatorname{SNR}_{2}^{(\text {pro })}\left(l, J_{2}\right) \\
=\frac{\left|g_{1}\left(l, J_{2}\right)\right|^{2}+\left|g_{2}\left(l, J_{2}\right)\right|^{2}}{\sigma_{z}^{2}}, l \in A \\
=\frac{\left|\sum_{m=1}^{M} h_{1, m}\left(l, J_{2}\right) v_{1, m}(l)\right|^{2}+\left|\sum_{m=1}^{M} h_{2, m}\left(l, J_{2}\right) v_{2, m}(l)\right|^{2}}{\sigma_{z}^{2}} .
\end{gathered}
$$

\section{IV. 모의 실험 및 성능 분석}

본 장에서는 모의 실험을 통하여, 제안하는 다중 셀 전송 다양성 기법과 기존 방법 간의 성능을 비 교한다. 두 개의 기지국이 협력하여 셀 경계 사용자 $\mathrm{UE}_{0}$ 에게 데이터를 전송하는 환경이고, 각 기지국에 서의 송신 안테나 개수는 4 개, 셀 경계 사용자 $\mathrm{UE}_{0}$ 에서의 수신 안테나 개수는 1 개라고 가정하였다.
4세대 이동통신 시스템인 3GPP LTE 시스템에서 사용하는 대표적인 단말기 피드백 방법은, 단말기가 $5 \mathrm{msec}$ 마다 채널에 대한 정보를 기지국으로 피드백 하고, 단말기의 피드백 시점부터 기지국의 데이터 스케줄링 시점까지의 시간 간격은 보통 $6 \mathrm{msec}$ 정도 가 소요된다 ${ }^{[10]}$. 따라서, 단말기가 채널 추정하는 시 점부터 실제로 데이터를 수신 받는 시점까지의 시 간 간격은 최대 $11 \mathrm{msec}$ 가 발생할 수 있다. 따라서, 모의 실험에서는 $\Delta$ 를 $11 \mathrm{msec}$ 로 설정하였다. 그리 고, 채널 모델은 SCM-E Sub-urban Macro 모델을 사용하였다 ${ }^{11]}$.

셀 경계 사용자 $\mathrm{UE}_{0}$ 의 이동 속도는 $3 \mathrm{~km} / \mathrm{h}, 60$ $\mathrm{km} / \mathrm{h}, 120 \mathrm{~km} / \mathrm{h}$ 인 경우를 고려하였다. 이동 속도가 $3 \mathrm{~km} / \mathrm{h}$ 인 경우는 채널이 시간적으로 별로 변하지 않 는 환경이기 때문에, 기존 방법에서처럼 채널 이득 이 가장 큰 송신 안테나의 인덱스에 대한 정보가 유용하게 사용될 수 있는 시나리오이다. 반면에, 이 동 속도가 $120 \mathrm{~km} / \mathrm{h}$ 인 경우는 채널이 시간적으로 매우 빨리 변하는 환경이기 때문에, 기존 방법에서 와 같은 채널에 대한 피드백 정보가 쓸모 없어지는 환경이다.

OFDMA 시스템에 대한 파라미터들은 $3 \mathrm{GPP}$ LTE시스템에서 사용하는 파라미터들을 사용하였다 ${ }^{[12]}$. 즉, 이웃한 시간 슬롯 간의 시간 간격은 $67 \mu$ $\mathrm{sec}$ 를 사용하였으며, $\mathrm{UE}_{0}$ 에게 데이터를 전송하기 위하여 12 개의 이웃한 부반송파들을 사용하였다. 그 리고, $\mathrm{UE}_{0}$ 가 기지국으로 피드백하기 위한 채널을 추정할 때와 데이터를 검파하기 위한 채널을 추정 할 때에 채널 추정 오차는 존재하지 않는다고 가정 하였다. 제안하는 방법에서 사용한 프리코딩 벡터는 $3 \mathrm{GPP}$ LTE 시스템에서 송신 안테나의 개수가 4인 경우에 대한 프리코딩 벡터를 사용하였다.

그림 2는 평균 $\mathrm{SNR}$ 에 대한 검파기 출력 $\mathrm{SNR}$ 결과를 보여준다. 그림에서, 'Conv.'는 기존 방법 [9]에 대한 성능을 보여주는 그림이고, 'Proposed'는 본 논문에서 제안하는 방법에 대한 성능을 보여주 는 그림이다. 그리고, $\mathrm{UE}_{0}$ 의 이동 속도가 $3 \mathrm{~km} / \mathrm{h}$, $60 \mathrm{~km} / \mathrm{h}, 120 \mathrm{~km} / \mathrm{h}$ 인 경우에 대한 결과를 같이 보여 준다. 이 그림으로부터 제안하는 방법의 검파기 출 력 $\mathrm{SNR}$ 값이 기존 방법보다 항상 높다는 것을 알 수 있다. 이것은 기존 방법에서는 한 개의 송신 안 테나만을 사용하지만, 제안하는 방법에서는 프리코 딩 벡터를 적용함으로써 모든 송신 안테나를 동시 에 사용하기 때문에, 제안하는 방법의 검파기 출력 $\mathrm{SNR}$ 값이 기존 방법보다 송신 안테나의 개수에 비 
례해서 높게 나타나게 된다.

그림 3은 평균 $\mathrm{SNR}$ 에 대한 비트 오율 (Bit error rate, BER) 결과를 보여 준다. 이 그림으로부터 $\mathrm{UE}_{0}$ 의 이동 속도가 $3 \mathrm{~km} / \mathrm{h}$ 인 경우, 낮은 $\mathrm{SNR}$ 에서 는 제안하는 방법이 더 우수한 BER 성능을 나타내 지만, 높은 $\mathrm{SNR}$ 에서는 기존 방법이 더 우수한 $\mathrm{BER}$ 성능을 나타낸다는 것을 볼 수 있다. 이와 같 은 환경에서, 제안하는 방법이 항상 더 우수한 검파 기 출력 $\mathrm{SNR}$ 성능을 보임에도 불구하고 $\mathrm{BER}$ 성능 이 더 안 좋게 나오는 이유는, 제안하는 방법은 검 파기 출력 $\mathrm{SNR}$ 의 표준 편차가 큰 반면에, 기존 방 법은 단말기가 피드백한 송신 안테나 인덱스 정보 가 유용하게 사용되고 있고 이로 인해서 검파기 출 력 $\mathrm{SNR}$ 의 표준 편차가 작기 때문이다. 그리고, $\mathrm{UE}_{0}$ 의 이동 속도가 $60 \mathrm{~km} / \mathrm{h}$ 인 경우와 $120 \mathrm{~km} / \mathrm{h}$ 인 경우에는 제안하는 방법의 $\mathrm{BER}$ 성능이 기존 방법 보다 항상 우수하다는 것을 알 수 있다.

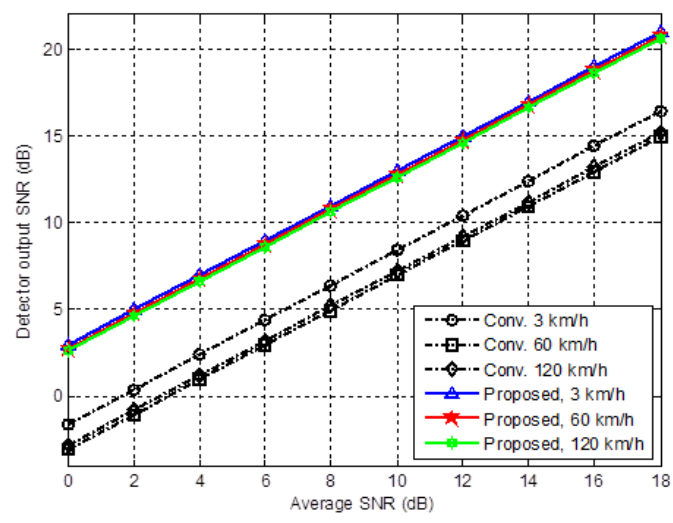

그림 2. 평균 $\mathrm{SNR}$ 에 대한 검파기 출력 $\mathrm{SNR}$

Fig. 2. Detector output SNR vs. average SNR

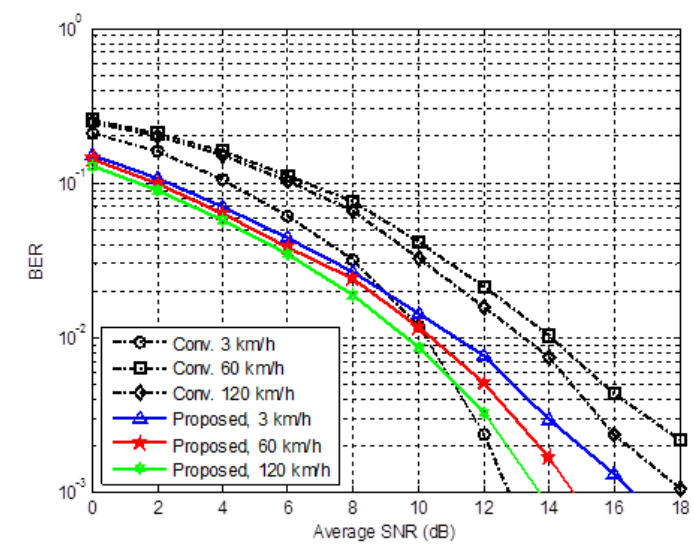

그림 3. 평균 $\mathrm{SNR}$ 에 대한 $\mathrm{BER}$ 결과

Fig. 3. BER vs. average SNR

\section{V. 결 론}

본 논문에서는 채널이 빠르게 변하는 환경에 적 합한 다중 셀 전송 다양성 기법에 대해서 제안하였 다. 제안하는 방법은 기지국이 채널에 대한 정보를 필요로 하지 않기 때문에, 단말기가 채널에 대한 정 보를 기지국으로 피드백하기 위한 피드백 비트 수 를 필요로 하지 않는다. 그리고, 모든 송신 안테나 에 대하여 프리코딩 벡터를 적용하고 데이터 전송 시 모든 송신 안테나를 동시에 사용하기 때문에 기 지국이 사용할 수 있는 전력을 최대로 사용하는 장 점이 있다. 또한, 이웃한 부반송파들 간에 서로 다 른 프리코딩 벡터를 적용함으로써, 수신 신호가 여 러 부반송파에 걸쳐서 큰 채널 감쇄를 겪는 것을 피하도록 하였다. 모의 실험을 통해, 단말기의 이동 속도가 빠른 경우에는 제안하는 다중 셀 전송 다양 성 기법이 기존의 기법보다 더 우수한 성능을 갖는 다는 것을 보였다.

\section{참 고 문 헌}

[1] L. Zheng and D. N. C. Tse, "Diversity and multiplexing: A fundamental tradeoff in multiple-antenna channels," IEEE Trans. Inf. Theory, vol. 49, pp. 1073-1096, May 2003.

[2] 조명주, 변윤식, "다중 사용자 $\mathrm{MIMO}$ 시스템에서 최소 제곱 기법을 이용한 새로운 간섭 정렬 기법," 한국통신학회논문지, 37A(06), pp. 488-496, 2012 년 6월.

M.-J. Jo, Y.-S. Byun, "New interference alignment technique using least square method in multi-user MIMO systems," J. Korea Inform. Commun., Society, 37A, pp. 488-496, Jun. 2012.

[3] S. Almouti, "A simple transmit diversity technique for wireless communications," IEEE J. Sel. Areas Commun., vol. 16, pp. 1451-1458, Oct. 1998.

[4] J. Kim and S. L. Ariyavistakul, "Optimum 4-transmit antenna STBC/SFBC with angle feedback and a near optimum 1-bit feedback scheme," IEEE Commun.Letters, vol. 11, pp. 868 - 870, Nov. 2007.

[5] I. Choi, J.-K. Kim, and I. Lee, "Alamouti-codes based four-antenna transmission schemes with phase feedback," IEEE Commun. Letters, vol. 
13, pp. 749-751, Oct. 2009.

[6] T. D. Novla, R. K. Ganti, A. Ghosh, and J. G. Andrews, "Analytical evaluation of fractional frequency reuse for OFDMA cellular networks," IEEE Trans. Wireless Commun., vol. 10, pp. 4294-4305, Dec. 2011.

[7] D. Gesbert, S. Hanly, H. Huang, S. S. Shitz, O. Simeone, and W. Yu, "Multi-cell MIMO cooperative networks: A new look at interference," IEEE J. Sel. Areas Commun., vol. 28, pp. 1380-1408, Dec. 2010.

[8] A. Tolli, M. Codreanu, and M. Juntti, "Cooperative MIMO-OFDM cellular system with soft handover between distributed base station antennas," IEEE Trans. Wireless Commun., vol. 7, pp. 1428-1440, Apr. 2008.

[9] S. Chae and D. I. Kim, "Antenna selected space-time block code coordinated multi-cell transmission," in IEEE PIMRC, pp. 2228-2232, 2010.

[10] 3GPP TR 36.814 v1.6.2, Further advancements for E-UTRA, Physical layer aspects (Release 9), Feb. 2010.

[11] D. S. Baum, J. Salo, G. Del Galdo, M. Milojevic, P. Kyosti, and J. Hansen, "An interim channel model for beyond-3G systems," in Proc. IEEE VTC, May 2005.

[12] 3GPP TS 36.211 v10.2.0, Evolved Universal Terrestrial Radio Access (E-UTRA); Physical Channels and Modulation (Release 10), Jun. 2011.
서 방 원 (Bangwon Seo)

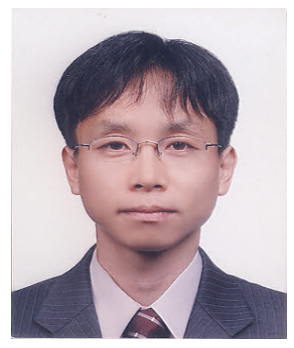

1997년 2월 한국과학기술원 전 기 및 전자공학과 공학사 1999년 2월 한국과학기술원 전

기 및 전자공학과 공학석사 2010년 2월 한국과학기술원 전

기 및 전자공학과 공학박사 2004년 11월 현재 한국전자통

신연구원 선임연구원

<관심분야> 이동통신 기술, 통신 신호처리, $\mathrm{MIMO}$, OFDM, CDMA, Cognitive Radio 